\title{
Molecular Mechanisms Lead to Sex-Specific COVID-19 Prognosis and Targeted Therapies
}

\author{
Thushara Galbadage ${ }^{1}$, Brent M. Peterson ${ }^{1}$, Jeffrey S. Wang ${ }^{2}$, Avishka Jayasekara ${ }^{3}$, \\ Danny A. Ramirez ${ }^{4}$, Joseph Awada ${ }^{4}$, John P. Walsh ${ }^{3}$ and Richard S. Gunasekera ${ }^{4 *}$ \\ ${ }^{1}$ Department of Kinesiology and Health Science, Biola University, La Mirada, CA, United States, ${ }^{2}$ Department of Infectious \\ Diseases, Southern California Permanente Medical Group, Pasadena, CA, United States, ${ }^{3}$ Leonard Davis School of \\ Gerontology, University of Southern California, Los Angeles, CA, United States, ${ }^{4}$ Department of Chemistry, Physics, and \\ Engineering, Biola University, La Mirada, CA, United States
}

OPEN ACCESS

Edited by:

Siva G. Somasundaram,

Salem International University, United States

Reviewed by:

Gjumrakch Aliev,

GALLY International Biomedical Research, United States

Yehuda Julyus Shoenfeld,

Sheba Medical Center, Israel

*Correspondence:

Richard S. Gunasekera

richard.gunasekera@biola.edu

Specialty section:

This article was submitted to Infectious Diseases-Surveillance,

Prevention and Treatment,

a section of the journal

Frontiers in Medicine

Received: 30 July 2020 Accepted: 05 November 2020 Published: 08 December 2020

Citation:

Galbadage T, Peterson BM, Wang JS, Jayasekara A, Ramirez DA, Awada J, Walsh JP and Gunasekera RS (2020)

Molecular Mechanisms Lead to Sex-Specific COVID-19 Prognosis and Targeted Therapies.

Front. Med. 7:589060.

doi: 10.3389/fmed.2020.589060
Clinical and epidemiological studies have identified male sex as an important risk factor for COVID-19 clinical outcomes and mortality. This raises the question as to how this risk factor can be addressed in the prognosis, clinical management, and the treatment of patients with Coronavirus disease 2019 (COVID-19). Currently, there are no guidelines or protocols to help alter the course of sex-specific COVID-19 prognosis, especially in severe disease presentations. This is partly due to the lack of research studies characterizing the differences in male vs. female host response to the severe acute respiratory syndrome Coronavirus-2 (SARS-CoV-2) infection and a lack of a well-rounded understanding of the molecular mechanisms involved. Here, we discuss three distinct but interconnected molecular-level differences in males and females that likely play an essential role in the COVID-19 prognosis. We review interactions of SARS-CoV-2 with host cell angiotensin-converting enzyme 2 (ACE2) in the viral entry between males vs. females and discuss the differential regulation of the renin-angiotensin system (RAS) between the two sexes. Next, we present immune response disparities and how immune function and endocrine regulation may render males increasingly vulnerable to severe COVID-19. We describe the interconnected roles of these three regulatory systems in males and females in response to SARS-CoV-2 infection. Finally, we highlight the clinical implications of these mechanisms to patients with COVID-19 and propose putative targeted therapies that can help reduce COVID-19 severity in those critically ill.

Keywords: SARS-CoV-2, coronavirus, male, sex, ACE2, immunity, endocrine, androgen

\section{INTRODUCTION}

The severe acute respiratory syndrome Coronavirus 2 (SARS-CoV-2) infections elicit a wide variety of clinical outcomes among patients. As the Coronavirus disease 2019 (COVID-19) pandemic unfolds, a greater understanding of disease-related risk factors is developing. For example, primary risk factors for severe COVID-19 are advanced age, comorbidities including chronic respiratory disease, cardiovascular disease, diabetes, and hypertension (1-4). Additionally, multiple studies stratifying COVID-19 cases and mortality rates by sex have demonstrated sexrelated divergence between males and females in severe and fatal cases $(2,5-9)$. More recently, systematic reviews of COVID-19 clinical studies have helped establish the male sex as a substantial risk factor for poor prognostic outcomes of COVID-19 and higher mortality rates (10-12). 
Studies have also noted that social risk factors such as smoking and tobacco use may predispose males to more severe forms of COVID-19 (13-16). We examined sex-specific COVID-19 clinical outcomes and observed that the male sex was a distinct risk factor across the world, irrespective of region or country (10). While social factors may play a role in Coronavirus disease severity, mounting evidence makes it undeniable that there are likely sex-specific molecular mechanistic differences that make males more susceptible to severe COVID-19. There are inherent sex-specific differences in males vs. females. These differences may provide a more comprehensive explanation for observed sex-specific COVID19 clinical outcomes. For example, at the molecular level, males and females respond to various infections differently in terms of immune response and regulation of endocrine function (17-21). Currently, however, sex-specific host response differences to SARS-CoV-2 at the molecular level have yet to be clearly defined.
Our review examines three categories of molecular-level differences in males and females that are likely to lead to severe COVID-19 disease in males. These include (1) the molecular interaction of angiotensin-converting enzyme 2 (ACE2) with SARS-CoV-2 and its modulation within the reninangiotensin system (RAS), (2) sex-related endocrine differences in immune responses to pathogens, and (3) the effects of estrogen and androgens on regulation of ACE2 and RAS (Figure 1). Importantly, a better understanding of these particularly unique sex-specific differences in the severity of COVID-19 could result in the use of targeted therapy by clinicians to help avert lifethreatening diseases.

\section{ACE2 ACTS AS THE FUNCTIONAL RECEPTORS FOR VIRAL CELL ENTRY}

ACE2 is a homolog of the angiotensin-converting enzyme (ACE) that acts to modulate RAS by cleaving both angiotensin I (Ang-

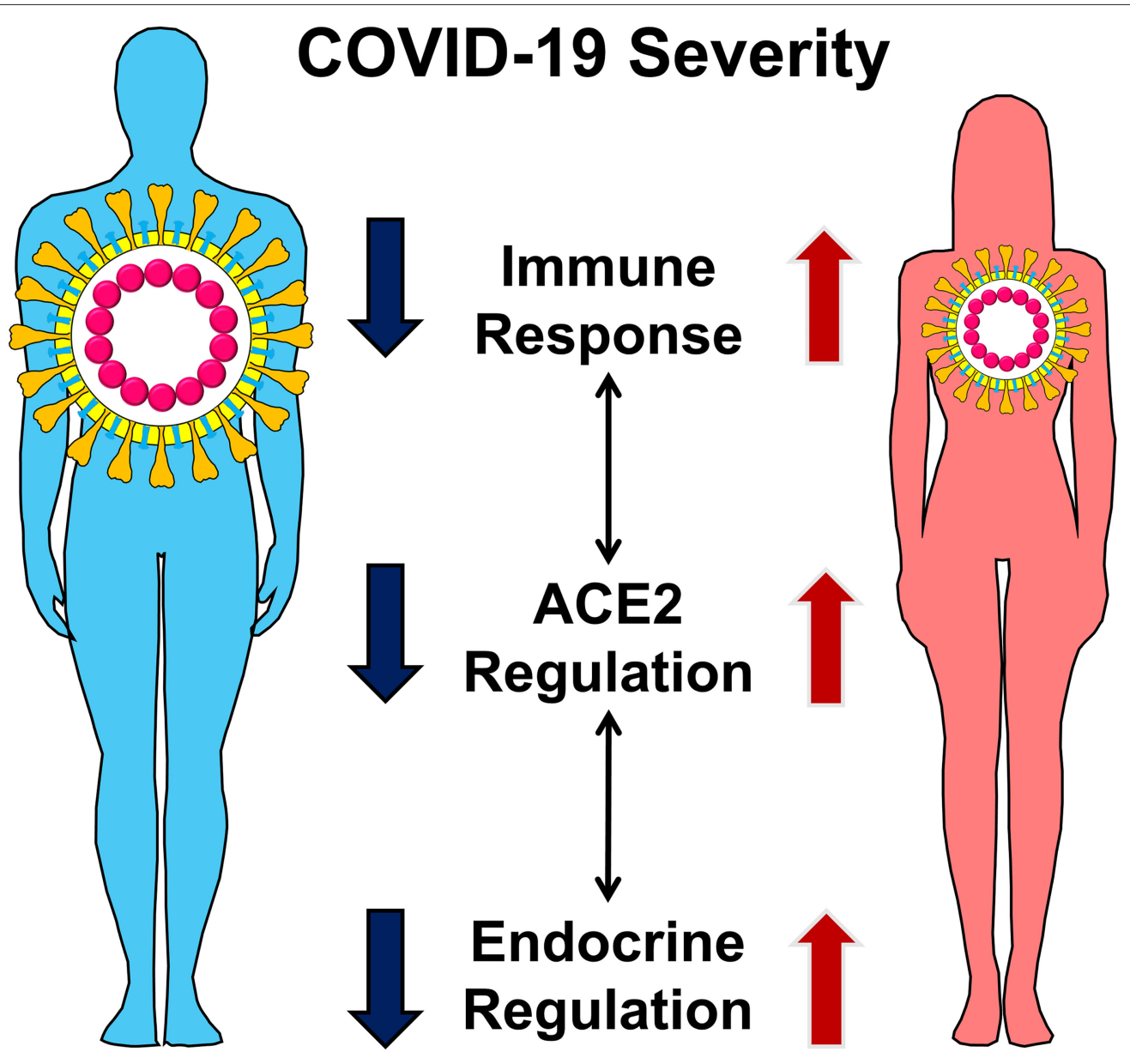

Male Response

Female Response

FIGURE 1 | Male and female display differences in COVID-19 severity. The differences in disease severity can be explained by sex-specific differences in the regulation of ACE2, immune response, and endocrine regulation. These distinct but interconnected molecular mechanisms lead to severe COVID-19 in men. 
I) and angiotensin II (Ang-II) (22, 23). With the COVID-19 pandemic, the role of ACE2 in the pathogenesis of SARS-CoV2 has gained broad interest, especially for its connection with the RAS and its clinical implications (24). SARS-CoV-2 shares high amino acid sequence homology with SARS-CoV-1 from the 2002-2003 SARS outbreak. SARS-CoV-1 enters into host cells using the viral spike (S) protein as a ligand to the host ACE2 receptor (25-27). Similarly, ACE2 is the functional host receptor for SARS-CoV-2, acting as an epithelial entry point in the respiratory tract (28). The SARS-CoV-2 S protein engages the ACE2 and uses the host serine protease TMPRSS2 for S-priming, fusion, and entry. Binding of SARS-CoV-2 to ACE2 receptors reportedly occurs with 10-20 times higher binding affinity than SARS-CoV-1, making it more virulent and transmissible (2830). Thus, increased ACE2 expression may facilitate the viral cell entry process. The internalization of ACE2 with SARS-CoV2 leads to a decrease in the amount of ACE2 receptors on the cell surface, and this affects the delicate RAS balance (31). ACE2 and RAS are essential for blood pressure regulation and electrolyte homeostasis (32). This connection led clinicians to be concerned about the use of RAS system modulating medications like angiotensin receptor blockers (ARBs) and ACE inhibitors as they managed their patients $(33,34)$. The safe use of these hypertensive mediations amidst the COVID-19 pandemic is currently an area of active research (35).

\section{MALES AND FEMALES DIFFERENTIALLY EXPRESS ACE2 LEADING TO DIFFERENT COVID-19 OUTCOMES}

Androgens play a role in the RAS by promoting the expression of angiotensinogen and increases the plasma activity of renin (36). In contrast, estrogen downregulates the expression of AT1R, ACE, and decreases the plasma activity of renin (37). Besides modulating ACE activity, estrogen upregulates the expression of ACE2, AT2R, and the mitochondrial assembly receptor (Mas R) (19). This is a critical difference in the regulation of the RAS by androgen and estrogen. The activation of the ACE2 and AT1R axis by androgen leads to inflammation, hypertension, vasoconstriction, fibrosis, and cell proliferation $(38,39)$. In comparison, the activation of the alternative angiotensin (17) [Ang-(1-7)], AT2R, and Mas R axis by estrogen leads to protective effects including anti-inflammation, hypotension, vasodilatation, and apoptosis (40, 41). Ang-II levels among patients with COVID-19 is strongly associated with viral load and lung injury. Plasma samples of Ang-II in patients with COVID-19 revealed substantial elevations and was associated with viral load and lung injury (42). Clinically elevated AngII can result in detrimental physiological effects, stimulating the adrenal gland and, subsequently, increasing blood pressure. SARS-CoV-2 uses ACE2 receptors for viral cell entry and thereby downregulates cell surface ACE2 (28). Downregulating ACE2 reduces the conversion of Ang-II to Ang-(1-7), which can lead to the increased activity of AT1R its downstream effects.

Regulation of RAS has been demonstrated to differ between males and females in animal models. For example, in a study, male rats expressed higher Ang-II and angiotensin II receptor type 1 (AT1R) as opposed to female rats with higher Angiotensin II Receptor Type 2 (AT2R) and Ang-(1-7) (43). Additionally, orchiectomy decreased enzymatic function in male mice, while ovariectomy increased hypertrophy and ACE2 in female mice. Young-adult rats ( 3 months old) had a higher ACE2 expression compared to older rats (24 months old), respectively (44). These observations may help explain the paradoxical decrease in the level of ACE2 receptors observed in lung tissue of patients infected with SARS-CoV-2. Interestingly, observations of reduced ACE2 expression in patients who were infected with SARS-CoV-1 may suggest mechanisms that lead to SARS (4547). These results further support that estrogen and androgens play an essential role in the regulation of the RAS.

Males express more ACE and ACE2 and thus, SARS-CoV-2 binding to ACE2 and its subsequent internalization removing this critical blood pressure reducing mechanism (48). The balance of ACE/ACE2 is toward ACE2 in females, and this relative difference in expression may convey protection by reducing blood pressure (49). These sex-differences in ACE2 are likely contributing to sex differences observed in COVID19 -related infection, morbidity, and mortality $(48,49)$. Femalespecific immune response and ACE2 regulation also work together to maintain both immune function and blood pressure homeostasis (50).

\section{SEX DIFFERENCES IN IMMUNE RESPONSE LEAD TO DIFFERENCES IN DISEASE PROGNOSIS}

Men are more susceptible to viral, bacterial, fungal, and parasitic infections, while women are more likely to suffer from autoimmune disease $(18,51-54)$. Women also mount superior immunity in response to vaccinations $(52,55,56)$. Sexbased vulnerability to SARS-Cov-2 infection and the severity of COVID-19 disease are likely linked to females having stronger innate and adaptive immunity and associated sex-differences in cytokine release and inflammatory response (48). Sex-based differences in cellular immune responses and inflammation are linked to $\mathrm{X}$ chromosome encoded genes, and later on, the differential impact of estrogen vs. androgen on immune function $(18,54,56)$. Several genes found on both X and Y chromosomes and sex hormones direct hematopoietic myeloid and lymphoid lineage profiles, subsequent cell development and surface protein expression, and cytokine production (18, 54, 56). Females show higher $\mathrm{CD} 4+$ cell counts and a higher CD4+/CD8+ ratio, with more active and more numerous cytotoxic $\mathrm{T}$ - and T-suppressor cells (18). For SARS-CoV-2, a more inhibited adaptive immune response in females who have more T-cells is represented by lower mortality rates of females in comparison with males $(6,8,9)$.

Several genes influencing immune cell function, and immune cell protein expression are located on X chromosomes (51, 54). These $X$-linked genes control the expression of pattern recognition receptors like TLR-7 and TLR-8, CD132, and CD40 in both innate and adaptive immune cells and modulators of 
NF-kappa-B transcription factor $(51,54)$. The X chromosome also contains a large number of micro-RNAs (miRNAs) involved in the modulation of immune function and the gene for the androgen receptor (AR) (Xq12 location) (54). Besides the malespecific functions of the AR, it is vital in the modulation of antibody production and the transcription of the serine protease TMPRSS2 (57). Therefore, AR plays a critical role in the SARSCoV-2 viral cell entry, as TMPRSS2 is required for the priming of the $S$ protein before cell entry (28). Males having a higher level of AR compared to females may result in an increased level of COVID-19 susceptibility.

\section{ENDOCRINE REGULATION OF THE IMMUNE RESPONSE IN MALES AND FEMALES}

In general, estrogen acts to activate the immune system, while androgens act to inhibit immune function (54). Estrogen receptors (ER $\alpha$ and ER $\beta$ ) are found on hematopoietic progenitor cells, and they show unique expression in differentiated lymphocytes ( $\mathrm{T}$ - and B-cells) and myeloid cells (mast cells, macrophages, dendritic cells, and natural killer cells) $(56,58)$. Estrogen binding to receptors in tissue invaded by the immune system can also reduce oxidative and apoptotic damage that can serve as a trigger for initiating platelet aggregation and the coagulation cascade (53). Females show higher myeloid phagocytic activity, and myeloid cell antigen presentation is superior to that found in males (18). Estrogen modulates the function of both CD4+ and CD8+ T-cells and myeloid cell lines. Estrogen increases the expression and release of TH1 pro-inflammatory cytokines (IL-12, TNF- $\alpha$, IFN- $\gamma$ ) and reduces the release of TH2 anti-inflammatory cytokines IL-10, IL-4 and TGF- $\beta$ in a concentration-dependent manner $(54,58)$. Estrogen and androgen bind to innate immune cells resulting in activating and suppressing effects, respectively $(53,54)$. Analysis of innate immunity shows female dendritic cells are more responsive to viral infections, and they show increased production of INF- $\alpha(51,54)$. This female-linked difference in dendritic cell function is influenced by estrogen modulation of antigen recognizing Toll-like receptor 7 (TLR7). Many of these sex-based differences are retained after menopause and seen before puberty, indicating a pivotal role played by X chromosome gene expression independent of hormone receptor activation [54). This regulation highlights the interconnected role of the immune response and the endocrine regulation that leads to sex-specific disease outcomes $(43,52,59)$.

\section{SEX-SPECIFIC MOLECULAR MECHANISMS REGULATE COVID-19 SEVERITY}

The RAS function, immune response, and the endocrine regulation are interconnected in their response to SARS-CoV-2 (Figure 2). ACE2 plays a central role in the observed sex-specific disparities in COVID-19 severity. ACE2 is the receptor for viral cell entry, and TMPRSS2 is essential for priming of the viral
$S$ protein before viral cell entry can happen. The transcription of TMPRSS2 is under the control of the AR, which is located on the X chromosome (Xq12). With the entry of SARS-CoV2, ACE2 is downregulated, and the action of Ang-II increases. This leads to greater inflammation, fibrosis, and acute lung injury, causing severe COVID-19 (Figure 2). The ACE2 gene is also located on the $\mathrm{X}$ chromosome (Xp22.2) and is regulated by estrogen. Estrogen causes increased levels of ACE2, which cleaves Ang-II to Ang-(1-7). ACE2 causes the activation of the Ang-(1-7)/Mas R/AT2R axis and the inhibition of the ACE/AngII/AT1R axis. Therefore, increased levels of ACE2 cause an antiinflammatory response, reduce fibrosis and protects the lungs from acute injury. This leads to a less severe form of COVID-19 (Figure 2). These sex-specific molecular mechanisms involved in SARS-CoV-2 infections offer potential targets for therapy to help reduce the severity of the disease.

\section{CLINICAL PERSPECTIVE ON COVID-19 PROGNOSIS AND CURRENT THERAPY}

While any person can acquire COVID-19, there tends to be a higher rate of disease in males compared to females, and this holds regardless of where on the spectrum of clinical severity the disease $(6,8,10)$. The predominantly described symptoms of COVID-19 usually involve some combination of fever, cough, and shortness of breath. However, other symptoms have also been described, including headache, chills, fatigue, anosmia, sore throat, congestion, rhinorrhea, nausea, diarrhea, and myalgias (60). In the majority of patients, COVID-19 symptoms stay mild enough to allow for recovery at home. Still, a significant minority of patients will progress in their symptoms to the point where they require hospitalization. Patients who suffer from the severe form of the disease may have a hyper-inflammatory response to the viral infection, also described as a "cytokine storm," which then leads to some of the more catastrophic clinical findings, including acute respiratory distress syndrome ARDS (61).

A variety of pharmacotherapies have been tried that target both the virus itself and the immune response. Some of the most promising include remdesivir and dexamethasone. Remdesivir is an anti-viral developed initially in 2015 for the treatment of Ebola. Remdesivir is a prodrug whose active metabolites interfere with the action of viral RNA-dependent RNA polymerase, ultimately causing a decrease in viral RNA production. Preliminary results from the adaptive COVID-19 clinical trial sponsored by the National Institute of Allergy and Infectious Diseases demonstrate a significant reduction in time to recovery for patients on remdesivir when compared to placebo and a trend toward improved mortality $(62,63)$. Dexamethasone, a synthetic corticosteroid with potential utility in tamping down inflammation, was found in the RECOVERY trial was found to have reduced deaths by one-third in ventilated patients and by one fifth in other patients receiving oxygen only (64). Patients who do poorly, as described above, tend to be male and tend to have underlying comorbidities. Longer than average days of mechanical ventilation have been described in these severely ill patients. Death is often from progressive, 


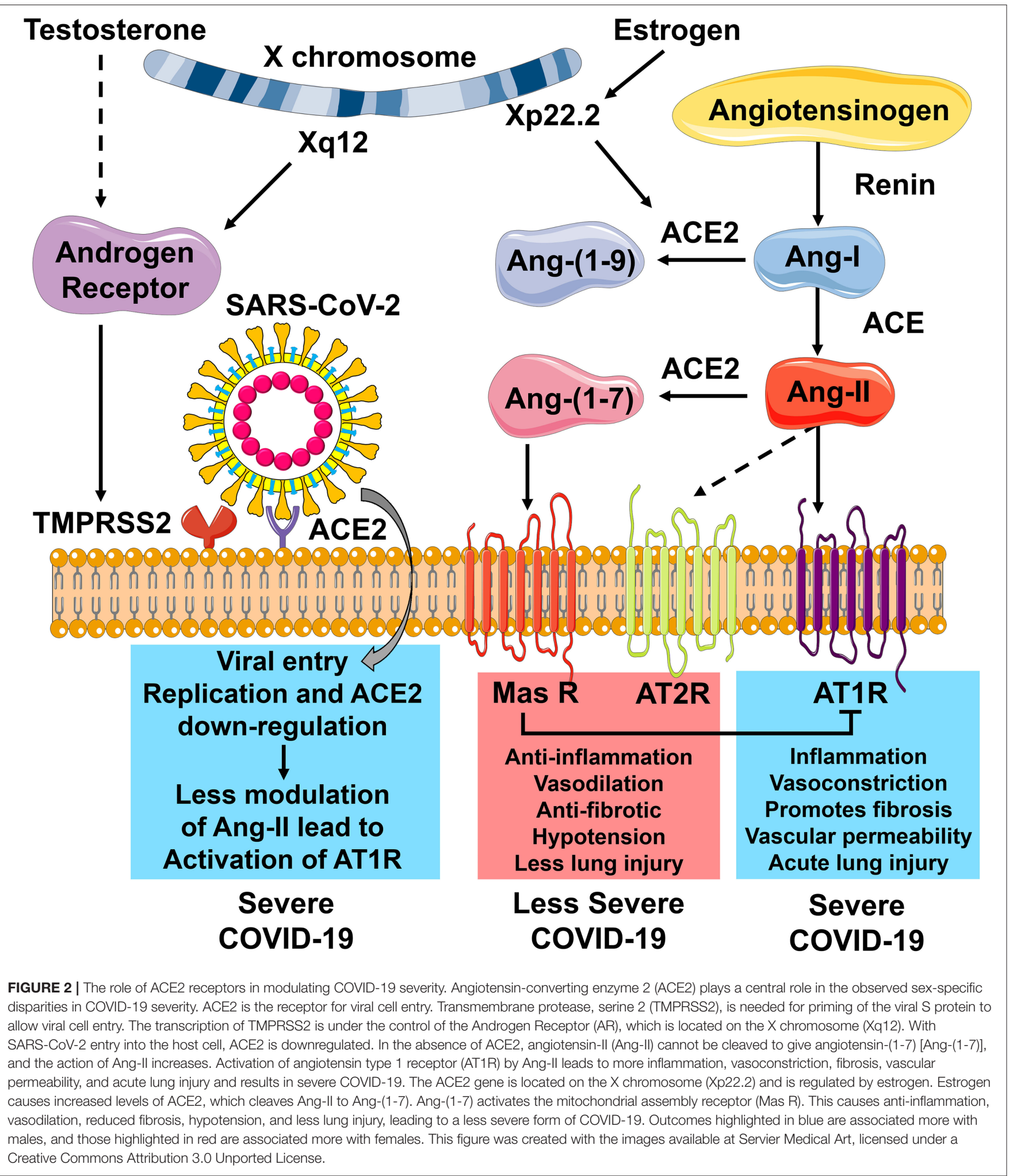

refractory pulmonary failure, but other organ systems have also been seen to be affected, including renal failure, cardiac injury, and thromboembolic events. Clinicians will benefit knowing male patients presenting with COVID-19 have a higher chance of experiencing rapid clinical deterioration compared to their female counterparts. 


\section{ANTI-ANDROGENS AS POTENTIAL TARGETED THERAPY FOR COVID-19}

With increasing evidence of sex-specific COVID-19 prognosis, there is a renewed interest in looking into the use of targeted clinical therapy. Anti-androgen therapy, including the use of 5alpha reductase inhibitors in male patients, is currently being studied $(65,66)$. In a study looking at prostate cancer patients' risk of contracting COVID-19, those that were on androgendeprivation therapies (ADTs) showed a partial protective effect (67). Since AR controls the transcription of TMPRSS2, this may serve as a potential targeted therapy to reduce the severity of COVID-19 in male patients. This ultimately begs the question of whether anti-androgen therapies should be given to male patients with COVID-19.

Several dietary compounds have been proven to work as 5-alpha reductase inhibitors and anti-androgenic therapeutics. Curcumin, the active ingredient in turmeric; lycopene, the red pigment found in tomato; and capsaicin, the chemical found in chili peppers, are known androgen inhibitors via their inhibitory properties in the metabolism of dihydroxy testosterone (68-72). These are well known also due to their preventative abilities to prevent prostate disease. Therefore, given the involvement of AR

\section{REFERENCES}

1. Guo W, Li M, Dong Y, Zhou H, Zhang Z, Tian C, et al. Diabetes is a risk factor for the progression and prognosis of COVID-19. Diabetes Metab Res Rev. (2020) 36:e3319. doi: 10.1002/dmrr.3319

2. Huang C, Wang Y, Li X, Ren L, Zhao J, Hu Y, et al. Clinical features of patients infected with 2019 novel coronavirus in Wuhan, China. Lancet. (2020) 395:497-506. doi: 10.1016/S0140-6736(20)30183-5

3. Onder G, Rezza G, Brusaferro S. Case-fatality rate and characteristics of patients dying in relation to COVID-19 in Italy. JAMA. (2020) 323:1775-6. doi: 10.1001/jama.2020.4683

4. Zhou F, Yu T, Du R, Fan G, Liu Y, Liu Z, et al. Clinical course and risk factors for mortality of adult inpatients with COVID-19 in Wuhan, China: a retrospective cohort study. Lancet. (2020) 395:1054-62. doi: 10.1016/S0140-6736(20)30566-3

5. Chen T, Wu D, Chen H, Yan W, Yang D, Chen G, et al. Clinical characteristics of 113 deceased patients with coronavirus disease 2019: retrospective study. BMJ. (2020) 368:m1091. doi: 10.1136/bmj.m1091

6. Jin J-M, Bai P, He W, Wu F, Liu X-F, Han D-M, et al. Gender differences in patients with COVID-19: focus on severity and mortality. Front Public Health. (2020) 8:152. doi: 10.3389/fpubh.2020.00152

7. Remuzzi A, Remuzzi G. COVID-19 and Italy: what next? Lancet. (2020) 395:1225-8. doi: 10.1016/S0140-6736(20)30627-9

8. Richardson S, Hirsch JS, Narasimhan M, Crawford JM, McGinn T, Davidson KW, et al. Presenting characteristics, comorbidities, and outcomes among 5700 patients hospitalized with COVID-19 in the New York City area. JAMA. (2020) 323:2052-9. doi: 10.1001/jama.2020.6775

9. Salje H, Tran Kiem C, Lefrancq N, Courtejoie N, Bosetti P, Paireau J, et al. Estimating the burden of SARS-CoV-2 in France. Science. (2020) 369:208-11. doi: 10.1126/science.abc3517

10. Galbadage T, Peterson BM, Awada J, Buck A, Ramirez D, Wilson J, et al. Systematic review and meta-analysis of sex-specific COVID-19 clinical outcomes. Front Med. (2020) 7:348. doi: 10.3389/fmed.2020.00348

11. Li LQ, Huang T, Wang YQ, Wang ZP, Liang Y, Huang TB, et al. COVID19 patients' clinical characteristics, discharge rate, and fatality rate of metaanalysis. J Med Virol. (2020) 92:577-83. doi: 10.1002/jmv.25757 in SARS-CoV-2 pathogenesis, these compounds may have some preventative potential against COVID-19. Our review puts the current research literature in perspective to help emphasize the importance of sex-specific differences in the clinical management of COVID-19 patients. While it may be too early to determine the effectiveness of such treatment, it highlights the evolution of medical practice in the treatment and prevention of infectious diseases to include sex-specific differences in pathogenesis.

\section{AUTHOR CONTRIBUTIONS}

All authors listed have made a substantial, direct and intellectual contribution to the work, and approved it for publication.

\section{FUNDING}

The work of RG and TG was supported in part by the Discovery Institute and the Peter \& Carla Roth Family.

\section{ACKNOWLEDGMENTS}

We acknowledge research student, Alison S. Buck, for her discussions on this research topic.

12. Zheng Z, Peng F, Xu B, Zhao J, Liu H, Peng J, et al. Risk factors of critical \& mortal COVID-19 cases: a systematic literature review and meta-analysis. $J$ Infect. (2020) 81:e16-25. doi: 10.1016/j.jinf.2020.04.021

13. Berlin I, Thomas D, Le Faou AL, Cornuz J. COVID-19 and smoking. Nicotine Tob Res. (2020) 22:1650-2. doi: 10.1093/ntr/ntaa059

14. Brake SJ, Barnsley K, Lu W, McAlinden KD, Eapen MS, Sohal SS. Smoking upregulates angiotensin-converting enzyme-2 receptor: a potential adhesion site for novel coronavirus SARS-CoV-2 (Covid-19). J Clin Med. (2020) 9:841. doi: $10.3390 / \mathrm{jcm} 9030841$

15. Cai G. Bulk and single-cell transcriptomics identify tobacco-use disparity in lung gene expression of ACE2, the receptor of 2019-nCov. medRxiv [Preprint]. (2020). doi: 10.1101/2020.02.05.20020107

16. Cai H. Sex difference and smoking predisposition in patients with COVID-19. Lancet Respir Med. (2020) 8:e20. doi: 10.1016/S2213-2600(20)30117-X

17. Hilliard LM, Sampson AK, Brown RD, Denton KM. The "his and hers" of the renin-angiotensin system. Curr Hypertens Rep. (2013) 15:71-9. doi: 10.1007/s11906-012-0319-y

18. Klein SL, Flanagan KL. Sex differences in immune responses. Nat Rev Immunol. (2016) 16:626-38. doi: 10.1038/nri.2016.90

19. Bukowska A, Spiller L, Wolke C, Lendeckel U, Weinert S, Hoffmann J, et al. Protective regulation of the ACE2/ACE gene expression by estrogen in human atrial tissue from elderly men. Exp Biol Med. (2017) 242:1412-23. doi: $10.1177 / 1535370217718808$

20. Taneja V. Sex hormones determine immune response. Front Immunol. (2018) 9:1931. doi: 10.3389/fimmu.2018.01931

21. Jaillon S, Berthenet K, Garlanda C. Sexual dimorphism in innate immunity. Clin Rev Allergy Immunol. (2019) 56:308-21. doi: 10.1007/s12016-017-8648-x

22. Bourgonje AR, Abdulle AE, Timens W, Hillebrands JL, Navis GJ, Gordijn SJ, et al. Angiotensin-converting enzyme 2 (ACE2), SARS-CoV-2 and the pathophysiology of coronavirus disease 2019 (COVID-19). J Pathol. (2020) 251:228-48. doi: 10.1002/path.5471

23. Gheblawi M, Wang K, Viveiros A, Nguyen Q, Zhong JC, Turner AJ, et al. Angiotensin-converting enzyme 2: SARS-CoV-2 receptor and regulator of the renin-angiotensin system: celebrating the 20th anniversary of the discovery of ACE2. Circ Res. (2020) 126:1456-74. doi: 10.1161/CIRCRESAHA.120. 317015 
24. Walls AC, Park YJ, Tortorici MA, Wall A, McGuire AT, Veesler D. Structure, function, and antigenicity of the SARS-CoV-2 spike glycoprotein. Cell. (2020) 181:281-92.e286. doi: 10.1016/j.cell.2020.02.058

25. Li W, Moore MJ, Vasilieva N, Sui J, Wong SK, Berne MA, et al. Angiotensinconverting enzyme 2 is a functional receptor for the SARS coronavirus. Nature. (2003) 426:450-4. doi: 10.1038/nature02145

26. Li W, Sui J, Huang IC, Kuhn JH, Radoshitzky SR, Marasco WA, et al. The S proteins of human coronavirus NL63 and severe acute respiratory syndrome coronavirus bind overlapping regions of ACE2. Virology. (2007) 367:367-74. doi: 10.1016/j.virol.2007.04.035

27. Wu K, Li W, Peng G, Li F. Crystal structure of NL63 respiratory coronavirus receptor-binding domain complexed with its human receptor. Proc Natl Acad Sci USA. (2009) 106:19970-4. doi: 10.1073/pnas.0908837106

28. Hoffmann M, Kleine-Weber H, Schroeder S, Kruger N, Herrler T, Erichsen $\mathrm{S}$, et al. SARS-CoV-2 cell entry depends on ACE2 and TMPRSS2 and is blocked by a clinically proven protease inhibitor. Cell. (2020) 181:271-80.e8. doi: $10.1016 /$ j.cell.2020.02.052

29. Galbadage T, Peterson BM, Gunasekera RS. Does COVID-19 spread through droplets alone? Front Public Health. (2020) 8:163. doi: 10.3389/fpubh.2020.00163

30. Wrapp D, Wang N, Corbett KS, Goldsmith JA, Hsieh CL, Abiona O, et al. Cryo-EM structure of the 2019-nCoV spike in the prefusion conformation. Science. (2020) 367:1260-3. doi: 10.1126/science.abb2507

31. South AM, Brady TM, Flynn JT. ACE2 (angiotensin-converting enzyme 2), COVID-19, and ACE inhibitor and Ang II (Angiotensin II) receptor blocker use during the pandemic: the pediatric perspective. Hypertension. (2020) 76:16-22. doi: 10.1161/HYPERTENSIONAHA.120.15291

32. Yim HE, Yoo KH. Renin-Angiotensin system - considerations for hypertension and kidney. Electrolyte Blood Press. (2008) 6:42-50. doi: 10.5049/EBP.2008.6.1.42

33. Trifirò G, Crisafulli S, Andò G, Racagni G, Drago F. Should patients receiving ACE Inhibitors or angiotensin receptor blockers be switched to other antihypertensive drugs to prevent or improve prognosis of novel coronavirus disease 2019 (COVID-19)? Drug Saf. (2020) 43:507-9. doi: 10.1007/s40264-020-00935-2

34. Zhang P, Zhu L, Cai J, Lei F, Qin JJ, Xie J, et al. Association of inpatient use of angiotensin-converting enzyme inhibitors and angiotensin ii receptor blockers with mortality among patients with hypertension hospitalized with COVID-19. Circ Res. (2020) 126:1671-81. doi: 10.1161/CIRCRESAHA.120.317134

35. Kanwal A, Agarwala A, Martin LW, Handberg EM, Yang E. COVID-19 and Hypertension: What We Know and Don't Know. American College of Cardiology (2020). Available online at: https://www.acc.org/latest-incardiology/articles/2020/07/06/08/15/covid-19-and-hypertension (Accessed July 20, 2020).

36. Reckelhoff JF. Gender differences in the regulation of blood pressure. Hypertension. (2001) 37:1199-208. doi: 10.1161/01.HYP.37.5.1199

37. McGuire BB, Watson RW, Pérez-Barriocanal F, Fitzpatrick JM, Docherty NG. Gender differences in the renin-angiotensin and nitric oxide systems: relevance in the normal and diseased kidney. Kidney Blood Press Res. (2007) 30:67-80. doi: 10.1159/000099150

38. Patel S, Rauf A, Khan H, Abu-Izneid T. Renin-angiotensin-aldosterone (RAAS): The ubiquitous system for homeostasis and pathologies. Biomed Pharmacother. (2017) 94:317-25. doi: 10.1016/j.biopha.2017.07.091

39. Song J, Hu B, Qu H, Wang L, Huang X, Li M, et al. Upregulation of angiotensin converting enzyme 2 by shear stress reduced inflammation and proliferation in vascular endothelial cells. Biochem Biophys Res Commun. (2020) 525:812-8. doi: 10.1016/j.bbrc.2020.02.151

40. McKinney CA, Fattah C, Loughrey CM, Milligan G, Nicklin SA. Angiotensin(1-7) and angiotensin-(1-9): function in cardiac and vascular remodelling. Clin Sci. (2014) 126:815-27. doi: 10.1042/CS20130436

41. Varagic J, Ahmad S, Nagata S, Ferrario CM. ACE2: angiotensin II/angiotensin(1-7) balance in cardiac and renal injury. Curr Hypertens Rep. (2014) 16:420. doi: 10.1007/s11906-014-0420-5

42. Liu Y, Yang Y, Zhang C, Huang F, Wang F, Yuan J, et al. Clinical and biochemical indexes from 2019-nCoV infected patients linked to viral loads and lung injury. Sci Chin Life Sci. (2020) 63:364-74. doi: $10.1007 /$ s11427-020-1643-8
43. Dalpiaz PL, Lamas AZ, Caliman IF, Ribeiro RFJr, Abreu GR, Moyses MR, et al. Sex hormones promote opposite effects on ACE and ACE2 activity, hypertrophy and cardiac contractility in spontaneously hypertensive rats. PLoS ONE. (2015) 10:e0127515. doi: 10.1371/journal.pone.0127515

44. Xie X, Chen J, Wang X, Zhang F, Liu Y. Age- and gender-related difference of ACE2 expression in rat lung. Life Sci. (2006) 78:2166-71. doi: 10.1016/j.lfs.2005.09.038

45. Kuba K, Imai Y, Rao S, Gao H, Guo F, Guan B, et al. A crucial role of angiotensin converting enzyme 2 (ACE2) in SARS coronavirus-induced lung injury. Nat Med. (2005) 11:875-9. doi: 10.1038/nm1267

46. Hamming I, Cooper ME, Haagmans BL, Hooper NM, Korstanje R, Osterhaus $\mathrm{AD}$, et al. The emerging role of ACE2 in physiology and disease. J Pathol. (2007) 212:1-11. doi: 10.1002/path.2162

47. Imai Y, Kuba K, Penninger JM. The discovery of angiotensin-converting enzyme 2 and its role in acute lung injury in mice. Exp Physiol. (2008) 93:543-8. doi: 10.1113/expphysiol.2007.040048

48. Gemmati D, Bramanti B, Serino ML, Secchiero P, Zauli G, Tisato V. COVID19 and individual genetic susceptibility/receptivity: role of ACE1/ACE2 genes, immunity, inflammation and coagulation. might the double Xchromosome in females be protective against SARS-CoV-2 compared to the single X-chromosome in males? Int J Mol Sci. (2020) 21:3474. doi: 10.3390/ijms21103474

49. Sriram K, Insel PA. A hypothesis for pathobiology and treatment of COVID19: the centrality of ACE1/ACE2 imbalance. Br J Pharmacol. (2020) 177:482544. doi: 10.1111/bph.15082

50. Crowley SD, Rudemiller NP. Immunologic effects of the Renin-Angiotensin system. J Am Soc Nephrol. (2017) 28:1350-61. doi: 10.1681/ASN.2016101066

51. Addo MM, Altfeld M. Sex-based differences in HIV type 1 pathogenesis. $J$ Infect Dis. (2014) 209:S86-92. doi: 10.1093/infdis/jiu175

52. Ruggieri A, Anticoli S, D'Ambrosio A, Giordani L, Viora M. The influence of sex and gender on immunity, infection and vaccination. Ann Ist Super Sanita. (2016) 52:198-204. doi: 10.4415/ANN_16_02_11

53. Ruggieri A, Gagliardi MC, Anticoli S. Sex-dependent outcome of hepatitis B and $\mathrm{C}$ viruses infections: synergy of sex hormones and immune responses? Front Immunol. (2018) 9:2302. doi: 10.3389/fimmu.2018.02302

54. Schurz H, Salie M, Tromp G, Hoal EG, Kinnear CJ, Möller M. The X chromosome and sex-specific effects in infectious disease susceptibility. Hum Genomics. (2019) 13:2. doi: 10.1186/s40246-018-0185-Z

55. Engler RJ, Nelson MR, Klote MM, VanRaden MJ, Huang CY, Cox NJ, et al. Half- vs full-dose trivalent inactivated influenza vaccine (2004-2005): age, dose, and sex effects on immune responses. Arch Intern Med. (2008) 168:240514. doi: 10.1001/archinternmed.2008.513

56. Ghosh S, Klein RS. Sex drives dimorphic immune responses to viral infections. J Immunol. (2017) 198:1782-90. doi: 10.4049/jimmunol.1601166

57. Clinckemalie L, Spans L, Dubois V, Laurent M, Helsen C, Joniau S, et al. Androgen regulation of the TMPRSS2 gene and the effect of a SNP in an androgen response element. Mol Endocrinol. (2013) 27:2028-40. doi: 10.1210/me.2013-1098

58. Salem ML. Estrogen, a double-edged sword: modulation of TH1- and TH2-mediated inflammations by differential regulation of $\mathrm{TH} 1 / \mathrm{TH} 2$ cytokine production. Curr Drug Targets Inflamm Allergy. (2004) 3:97-104. doi: $10.2174 / 1568010043483944$

59. Liu J, Ji H, Zheng W, Wu X, Zhu JJ, Arnold AP, et al. Sex differences in renal angiotensin converting enzyme 2 (ACE2) activity are $17 \beta$-oestradioldependent and sex chromosome-independent. Biol Sex Differ. (2010) 1:6. doi: 10.1186/2042-6410-1-6

60. CDC. Symptoms of Coronavirus. Centers for Disease Control and Prevention (2020). Available online at: https://www.cdc.gov/coronavirus/2019-ncov/ symptoms-testing/symptoms.html (accessed July 20, 2020).

61. Ye Q, Wang B, Mao J. The pathogenesis and treatment of the 'Cytokine Storm' in COVID-19. J Infect. (2020) 80:607-13. doi: 10.1016/j.jinf.2020.03.037

62. Beigel JH, Tomashek KM, Dodd LE, Mehta AK, Zingman BS, Kalil AC, et al. Remdesivir for the treatment of Covid-19 - preliminary report. $N$ Engl J Med. (2020) 383:1813-26. doi: 10.1056/NEJMoa2007764

63. NIH. NIH Clinical Trial Shows Remdesivir Accelerates Recovery From Advanced COVID-19. NIH (2020). Available online at: https://www.niaid.nih. gov/news- events/nih-clinical-trial-shows-remdesivir-accelerates-recoveryadvanced-covid-19 (accessed May 7, 2020). 
64. RECOVERY. Low-Cost Dexamethasone Reduces Death by up to One Third in Hospitalised Patients With Severe Respiratory Complications of COVID-19. Nuffield Department of Population Health (2020). Available online at: https:// www.recoverytrial.net/news/low-cost-dexamethasone-reduces-death-by-upto-one-third-in-hospitalised-patients-with-severe-respiratory-complicationsof-covid-19 (accessed Jun 6, 2020).

65. Duga S, Asselta R, Lazzeri M, Guazzoni G, Azzolini E, Buffi N, et al. Impact of anti-androgenic therapies on COVID-19: an observational study in male population from a COVID-19 regional centre of Lombardy (Italy). medRxiv [Preprint]. (2020). doi: 10.1101/2020.04.20. 20068056

66. Goren A, Vaño-Galván S, Wambier CG, McCoy J, Gomez-Zubiaur A, Moreno-Arrones OM, et al. A preliminary observation: Male pattern hair loss among hospitalized COVID-19 patients in Spain - A potential clue to the role of androgens in COVID-19 severity. J Cosmet Dermatol. (2020) 19:1545-7. doi: 10.1111 /jocd.13443

67. Montopoli M, Zumerle S, Vettor R, Rugge M, Zorzi M, Catapano $\mathrm{CV}$, et al. Androgen-deprivation therapies for prostate cancer and risk of infection by SARS-CoV-2: a population-based study $(\mathrm{N}=$ 4532). Ann Oncol. (2020) 31:1040-5. doi: 10.1016/j.annonc.2020. 04.479

68. Venier NA, Colquhoun AJ, Fleshner NE, Klotz LH, Venkateswaran V. Lycopene enhances the anti-proliferative and pro-apoptotic effects of capsaicin in prostate cancer in vitro. J Cancer Ther Res. (2012) 1:30. doi: 10.7243/2049-7962-1-30

69. Wan L, Tan H-L, Thomas-Ahner JM, Pearl DK, Erdman JW, Moran NE, et al. Dietary tomato and lycopene impact androgen signaling- and carcinogenesisrelated gene expression during early TRAMP prostate carcinogenesis. Cancer Prev Res. (2014) 7:1228-39. doi: 10.1158/1940-6207.CAPR14-0182
70. Srivilai J, Rabgay K, Khorana N, Waranuch N, Nuengchamnong $\mathrm{N}$, Wisuitiprot $\mathrm{W}$, et al. Anti-androgenic curcumin analogues as steroid 5-alpha reductase inhibitors. Med Chem Res. (2017) 26:1550-6. doi: 10.1007/s00044-017-1869-y

71. Gunasekera RS, Sewgobind K, Desai S, Dunn L, Black HS, McKeehan WL, et al. Lycopene and lutein inhibit proliferation in rat prostate carcinoma cells. Nutr Cancer. (2007) 58:171-7. doi: 10.1080/01635580701 328339

72. Gunasekera RS, Somasundaram S, Mitchell M, Arrambide D, Black HS Lutein inhibits growth of human prostate cancer cells and potentiates capsaicin, curcumin, and the traditional chemotherapy agent, camptothecin. Curr Top Phytochem. (2014) 12:1. Available online at: https://www.worldcat.o $\mathrm{rg} /$ title/lutein-inhibits-growth-of-human-prostate-cancer-cells-and-potentiat es-capsaicin-curcumin-and-the-traditional-chemotherapy-agent-camptothec in/oclc/5892027224\&referer=brief_results

Conflict of Interest: JW was employed by company Southern California Permanente Medical Group.

The remaining authors declare that the research was conducted in the absence of any commercial or financial relationships that could be construed as a potential conflict of interest.

Copyright (C) 2020 Galbadage, Peterson, Wang, Jayasekara, Ramirez, Awada, Walsh and Gunasekera. This is an open-access article distributed under the terms of the Creative Commons Attribution License (CC BY). The use, distribution or reproduction in other forums is permitted, provided the original author(s) and the copyright owner(s) are credited and that the original publication in this journal is cited, in accordance with accepted academic practice. No use, distribution or reproduction is permitted which does not comply with these terms. 